\title{
Differentiation between Phyllodes Tumors and Fibroadenomas Based on Mammographic Sonographic and MRI Features
}

\author{
Lale Duman $^{a} \quad$ Naciye S. Gezer ${ }^{a} \quad$ Pınar Balcı $^{a} \quad$ Canan Altay $^{a} \quad$ Işıl Başara ${ }^{a} \quad$ Merih G. Durak $^{b}$ \\ Ali ì. Sevinç ${ }^{c}$
}

${ }^{a}$ Department of Radiology, Faculty of Medicine, Dokuz Eylul University, Izmir, Turkey;

${ }^{b}$ Department of Pathology, Faculty of Medicine, Dokuz Eylul University, Izmir, Turkey;

${ }^{c}$ Department of General Surgery, Faculty of Medicine, Dokuz Eylul University, Izmir, Turkey

\section{Keywords}

Fibroadenoma · Differential diagnosis · Phyllodes tumor

\section{Summary}

Background: This study was performed to compare the mammographic, sonographic, and magnetic resonance imaging (MRI) characteristics of phyllodes tumors and fibroadenomas, which may resemble each other. Methods: Preoperative mammograms, B-mode and Doppler sonograms, and dynamic breast MRIs of 72 patients with pathologically proven fibroadenomas and 70 patients with pathologically proven phyllodes tumor were evaluated in this retrospective study. Statistical significance was evaluated using chi-square and Fisher's exact tests. Correlations in lesion size among radiological methods were examined by Pearson's correlation analysis. Results: The features that differed on mammogram were size, shape, and margin of the mass. Sonograms showed significant differences in size, shape, margin, echo pattern, and vascularization of the mass. Pearson's correlation analysis showed strong agreement among radiological methods in terms of assessment of size. Tumor size $\geq 3 \mathrm{~cm}$, irregular shape, microlobulated margins, complex internal echo pattern, and hypervascularity were significant findings of phyllodes tumors. Internal cystic areas on MRI were frequently associated with phyllodes tumors. Conclusion: Mammographic, sonographic, and MRI findings of fibroadenomas and phyllodes tumors could help radiologists to ascertain imaging-histological concordance and guide clinicians in their decision making regarding adequate follow-up or the necessity of biopsy.

\section{Introduction}

Phyllodes tumors of the breast account for $0.3-1.0 \%$ of mammary tumors $[1,2]$. However, these tumors may have a similar histopathological appearance and clinical and radiological features to fibroadenoma which is the most frequent benign tumor of the breast after fibrocystic disease [3]. The distinction between phyllodes tumor and fibroadenoma is clinically important, as approximately $20-30 \%$ of resected phyllodes tumors are malignant [1], and approximately $25 \%$ of malignant phyllodes tumors metastasize [4]. Phyllodes tumors must be treated surgically while fibroadenomas can be followed up safely without further investigation or can be treated with simple enucleation [5]. Moreover, wide excision of all types of phyllodes tumors with adequate margins is essential to avoid local recurrence and subsequent surgery [6-8], as the local recurrence rates of benign and borderline tumors are 20 and $>25 \%$, respectively [4].

There is substantial overlap in sonographic features between phyllodes tumors and fibroadenomas $[9,10]$. Only limited information on the magnetic resonance imaging (MRI) characteristics of phyllodes tumors is available [11]. This study was performed to compare the mammographic, sonographic, and MRI characteristics of phyllodes tumors and fibroadenomas, which may resemble each other.

\section{Materials and Methods}

This retrospective study was performed with institutional review board approval. A retrospective review of the medical records of our department for the period of 2000-2013 revealed 70 patients with phyllodes tumor discovered by excisional biopsy. 72 patients with fibroadenoma pathologically proven on excisional biopsy were selected randomly and matched to those with phyllodes tumors. Patients with lesions $<1 \mathrm{~cm}$ in diameter were not included in the study due

\section{KARGER \\ Fax +497614520714

\section{() 2016 S. Karger GmbH, Freiburg}

$1661-3791 / 16 / 0112-0123 \$ 39.50 / 0$ 
to the possible unfavorable effects of small lesion size on the radiological evaluation and to avoid bias in statistical analyses as phyllodes tumors are likely to be larger. Patients with a previous history of breast cancer and radiotherapy were not included in the study due to potential effects on imaging characteristics.

Preoperative mammograms and dynamic breast MRIs were reevaluated by 2 radiologists with 5 and 20 years of experience, respectively, blinded to the histopathological diagnoses of the lesions. The kinetic curve assessment of the dynamic MRIs was performed using ViewForum (Philips, Best, the Netherlands) and recorded using a picture archiving and communication system (PACS). Bmode and color Doppler sonography examinations were either recorded on hard copies or stored in the iSite archiving system (Philips, version 4.1.110.0). Sonographic data were obtained from these hard copies, images in the iSite archiving system, or from the results of sonographic examinations. The masses were classified using the American College of Radiology (ACR) Breast Imaging Reporting and Data System (BI-RADS) Atlas (5th edition) in all imaging methods. Decisions were reached by consensus.

All statistical tests were performed using SPSS 15.0 for Windows software (SPSS, Chicago, IL, USA). The statistical significance of the frequency of mammographic and sonographic features and MRI findings of phyllodes tumors and fibroadenomas was calculated. Statistical significance of the categorical variables was evaluated using chi-square and Fisher's exact tests. The largest diameter that could be measured determined the lesion size. Correlations between radiological methods for lesion size were measured by Pearson's correlation analysis. In all analyses, $\mathrm{p}<0.05$ indicated statistical significance.

\section{Results}

The numbers of patients evaluated by mammography, ultrasound, Doppler sonography, and MRI were 103, 140, 130, and 20, respectively. 102 patients were evaluated by both mammography and ultrasound while 1 patient was evaluated by mammography alone, 30 patients were evaluated by ultrasound alone, and 1 patient was evaluated by MRI alone. Pearson's correlation analysis showed strong agreement among the radiological methods used to assess size ( $\mathrm{p}<0.01 ; \mathrm{r}=0.89,0.94,0.95)$.

\section{Mammography}

Mammograms of 62 fibroadenomas and 41 phyllodes tumors were reevaluated. Statistically significant mammographic features differing between fibroadenomas and phyllodes tumors on mammograms included the size, shape, and margins of the mass ( $p$ $<0.001$ ). Fibroadenomas were smaller in size, ovoid in shape, and had circumscribed margins while phyllodes tumors were larger and irregular.

The lesion size was $>3 \mathrm{~cm}$ in $68.3 \%$ of phyllodes tumors while $85.5 \%$ of fibroadenomas were $<3 \mathrm{~cm}$. The lesion shape was oval in $74.2 \%$ of fibroadenomas but irregular in $68.3 \%$ of phyllodes tumors. Lesion margins were circumscribed in $77.4 \%$ of fibroadenomas and $29.3 \%$ of phyllodes tumors. Among the phyllodes tumors, $31.7 \%$ had microlobulated margins and $39 \%$ obscure or indistinct margins. Density was less than or equivalent to the surrounding breast parenchyma in $45.2 \%$ of fibroadenomas while $54.8 \%$ had a higher density. $31.7 \%$ of phyllodes tumors had a density equal to that of the surrounding breast parenchyma while $68.3 \%$ had a higher density. Uniform calcification was observed in $9.6 \%$ of fibroadenomas while $1.6 \%$ showed amorphous calcification. Among the phyllodes tumors, $12.1 \%$ had uniform and $2.4 \%$ amorphous
Table 1. Mammography findings in fibroadenomas and phyllodes tumors

\begin{tabular}{|c|c|c|c|}
\hline Lesion characteristics & $\begin{array}{l}\text { Fibroadenoma, } \\
\mathrm{n}(\%) \\
(\mathrm{n}=62)\end{array}$ & $\begin{array}{l}\text { Phyllodes } \\
\text { tumors, n (\%) } \\
(\mathrm{n}=41)\end{array}$ & $\mathrm{p}$ value \\
\hline \multicolumn{3}{|l|}{ Size } & $<0.001^{\mathrm{a}}$ \\
\hline$<3 \mathrm{~cm}$ & $53(85.5)$ & $13(31.7)$ & \\
\hline $3-4 \mathrm{~cm}$ & $9(14.5)$ & $21(51.2)$ & \\
\hline$>5 \mathrm{~cm}$ & $0(0)$ & $7(17.1)$ & \\
\hline \multicolumn{3}{|l|}{ Shape } & $<0.001^{\mathrm{a}}$ \\
\hline Round & $7(11.3)$ & $2(4.9)$ & \\
\hline Oval & $46(74.2)$ & $11(26.8)$ & \\
\hline Irregular & $9(14.5)$ & $28(68.3)$ & \\
\hline \multicolumn{3}{|l|}{ Margins } & $<0.001^{\mathrm{a}}$ \\
\hline Circumscribed & $48(77.4)$ & $12(29.3)$ & \\
\hline Microlobulated & $4(6.5)$ & $13(31.7)$ & \\
\hline Obscured & $9(14.5)$ & $10(24.4)$ & \\
\hline Indistinct & $1(1.6)$ & $6(14.6)$ & \\
\hline \multicolumn{3}{|l|}{ Density } & $0.381^{\mathrm{a}}$ \\
\hline $\begin{array}{l}\text { Less than the surround- } \\
\text { ing breast parenchyma }\end{array}$ & \\
\hline \multicolumn{4}{|l|}{$\begin{array}{l}\text { the surrounding breast } \\
\text { parenchyma }\end{array}$} \\
\hline $\begin{array}{l}\text { Greater than the sur- } \\
\text { rounding breast paren- } \\
\text { chyma }\end{array}$ & $34(54.8)$ & $28(68.3)$ & \\
\hline \multicolumn{3}{|l|}{ Calcification within the mass } & $1.000^{\mathrm{b}}$ \\
\hline Uniform & $6(9.6)$ & $5(12.1)$ & \\
\hline Amorphous & $1(1.6)$ & $1(2.4)$ & \\
\hline \multicolumn{3}{|c|}{$\begin{array}{l}\text { Features of the breast parenchyma } \\
\text { surrounding the mass }\end{array}$} & $1.000^{\mathrm{b}}$ \\
\hline Distortion and edema & $2(3)$ & $11(16)$ & \\
\hline Ductal ectasia & $0(0)$ & $1(1)$ & \\
\hline
\end{tabular}

${ }^{\mathrm{a} C h i-s q u a r e}$ test.

bFisher's exact test.

calcification. The breast parenchyma surrounding the mass had no significant features for differentiating between fibroadenomas and phyllodes tumors, although distortion and edema were detected more frequently in cases of phyllodes tumors. The details of the mammography findings are summarized in table 1.

\section{Sonography}

Sonograms of 71 fibroadenomas and 69 phyllodes tumors were reevaluated. The statistically significant features that differed between fibroadenomas and phyllodes tumors on sonograms included the size, shape, margins, and internal echo pattern of the mass $(\mathrm{p}<0.001)$. Fibroadenomas were smaller than phyllodes tumors. They were frequently hypoechoic with circumscribed margins while phyllodes tumors were irregular in shape with heterogeneous internal echogenicity and microlobulated margins. Among fibroadenomas, $76.1 \%$ were $<3 \mathrm{~cm}$ in size while the lesion size was $>3 \mathrm{~cm}$ in $72.4 \%$ of phyllodes tumors. The lesion shape was oval in $56.3 \%$ and irregular in $42.3 \%$ of fibroadenomas while $85.6 \%$ of phyllodes tumors were irregular. Lesion margins were circum- 
Table 2. Ultrasonographic findings in fibroadenomas and phyllodes tumors

\begin{tabular}{|c|c|c|c|}
\hline Lesion characteristics & $\begin{array}{l}\text { Fibroadenoma, } \\
\mathrm{n}(\%) \\
(\mathrm{n}=71)\end{array}$ & $\begin{array}{l}\text { Phyllodes } \\
\text { tumors, } \mathrm{n}(\%) \\
(\mathrm{n}=69)\end{array}$ & $\mathrm{p}$ value \\
\hline Size & & & $<0.001^{\mathrm{a}}$ \\
\hline$<3 \mathrm{~cm}$ & $54(76.1)$ & $19(27.6)$ & \\
\hline $3-4 \mathrm{~cm}$ & $16(22.5)$ & $37(53.6)$ & \\
\hline$>5 \mathrm{~cm}$ & $1(1.4)$ & $13(18.8)$ & \\
\hline Shape & & & $<0.001^{\mathrm{a}}$ \\
\hline Round & $1(1.4)$ & $1(1.4)$ & \\
\hline Oval & $40(56.3)$ & $9(13.0)$ & \\
\hline Irregular & $30(42.3)$ & $59(85.6)$ & \\
\hline Margins & & & $<0.001^{\mathrm{a}}$ \\
\hline Circumscribed & $55(77.5)$ & $23(33.3)$ & \\
\hline Microlobulated & $15(21.1)$ & $31(44.9)$ & \\
\hline Indistinct & $1(1.4)$ & $15(21.8)$ & \\
\hline Echo pattern & & & $<0.001^{\mathrm{a}}$ \\
\hline Hypoechoic & $55(77.5)$ & $14(20.3)$ & \\
\hline Heterogeneous & $16(22.5)$ & $55(79.7)$ & \\
\hline Posterior features & & & $0.618^{\mathrm{a}}$ \\
\hline Enhancement & $21(29.5)$ & $28(40.6)$ & \\
\hline Shadowing & $5(7.0)$ & $4(5.7)$ & \\
\hline Combined & $10(14.0)$ & $17(24.6)$ & \\
\hline Vascularity & & & $<0.001^{\mathrm{a}}$ \\
\hline Hypovascular & $47(70.1)$ & $14(22.2)$ & \\
\hline Hypervascular & $7(10.4)$ & $38(60.3)$ & \\
\hline Normal & $13(19.4)$ & $11(17.4)$ & \\
\hline
\end{tabular}

scribed in $77.5 \%$ of fibroadenomas and in $33.3 \%$ of phyllodes tumors. The margins of fibroadenomas were microlobulated in $44.9 \%$ of cases and indistinct in $21.8 \%$. Echo patterns were hypoechoic and heterogeneous in 77.5 and $22.5 \%$ of fibroadenomas and 20.3 and $79.7 \%$ of phyllodes tumors, respectively. Posterior enhancement was detected in $29.5 \%$ of fibroadenomas and $40.6 \%$ of phyllodes tumors.

The results of Doppler sonography examination of 67 fibroadenomas and 63 phyllodes tumors were reevaluated. Vascularization was significantly different between fibroadenomas and phyllodes tumors $(\mathrm{p}<0.001)$. Fibroadenomas were more frequently hypovascular $(70.1 \%)$ while phyllodes tumors tended to be hypervascular $(60.3 \%)$. The details of ultrasound and Doppler sonography findings are summarized in table 2.

\section{MRI}

The MRI findings of 10 fibroadenomas and 10 phyllodes tumors were reevaluated. Despite differences in mammographic and sonographic findings, there were no significant differences in the size or shape of the lesions on MRI, although fibroadenomas were more frequently $<3 \mathrm{~cm}$ in size $(7 / 10)$ and ovoid in shape (6/10) while phyllodes tumors were more frequently $>3 \mathrm{~cm}$ in size $(6 / 10)$ and irregular in shape (9/10). Fibroadenomas tended to be homogeneously enhanced (8/10) while phyllodes tumors showed heterogeneous enhancement (7/10); however, the difference was not sta-
Table 3. Magnetic resonance imaging findings in fibroadenomas and phyllodes tumors

\begin{tabular}{|c|c|c|c|}
\hline Lesion characteristics & $\begin{array}{l}\text { Fibroadenoma, } \\
\mathrm{n}(\%) \\
(\mathrm{n}=10)\end{array}$ & $\begin{array}{l}\text { Phyllodes } \\
\text { tumors, } \mathrm{n}(\%) \\
(\mathrm{n}=10)\end{array}$ & $\mathrm{p}$ value \\
\hline \multicolumn{3}{|l|}{ Size } & \multirow[t]{4}{*}{$0.369^{\mathrm{b}}$} \\
\hline$<3 \mathrm{~cm}$ & $7(70)$ & $4(40)$ & \\
\hline $3-4 \mathrm{~cm}$ & $3(30)$ & $3(30)$ & \\
\hline$>5 \mathrm{~cm}$ & $0(0)$ & $3(30)$ & \\
\hline \multicolumn{3}{|l|}{ Shape } & \multirow[t]{3}{*}{$0.057^{b}$} \\
\hline Oval & $6(60)$ & $1(10)$ & \\
\hline Irregular & $4(40)$ & $9(90)$ & \\
\hline \multicolumn{3}{|l|}{ Margins } & \multirow[t]{3}{*}{$1.000^{\mathrm{b}}$} \\
\hline Circumscribed & $10(100)$ & $9(90)$ & \\
\hline Irregular & $0(0)$ & $1(10)$ & \\
\hline \multicolumn{3}{|c|}{$\begin{array}{l}\text { Internal structure on T2-weighted TSE sequence } \\
\text { with fat suppression }\end{array}$} & \multirow[t]{5}{*}{$0.086^{\mathrm{b}}$} \\
\hline $\begin{array}{l}\text { Homogenous hyperin- } \\
\text { tense }\end{array}$ & $4(40)$ & $0(0)$ & \\
\hline Internal septations & $5(50)$ & $0(0)$ & \\
\hline Internal cystic areas & $0(0)$ & $6(6)$ & \\
\hline Both & $1(10)$ & $4(40)$ & \\
\hline \multicolumn{3}{|l|}{ Enhancement } & \multirow[t]{3}{*}{$0.069^{\mathrm{b}}$} \\
\hline Homogeneous & $8(80)$ & $3(30)$ & \\
\hline Heterogeneous & $2(20)$ & $7(70)$ & \\
\hline \multicolumn{3}{|c|}{ Signal intensity/time curve description } & \multirow[t]{4}{*}{$0.371^{\mathrm{a}}$} \\
\hline Type 1 & $6(60)$ & $4(40)$ & \\
\hline Type 2 & $4(40)$ & $5(50)$ & \\
\hline Type 3 & $0(0)$ & $1(10)$ & \\
\hline
\end{tabular}

${ }^{\mathrm{a} C h i}$-square test.

bFisher's exact test.

tistically significant. Hypointense internal septations were more frequently (6/10) associated with fibroadenomas while internal cystic areas were detected in all phyllodes tumors $(\mathrm{p}<0.001)$. The signal intensity/time curve was type 1 in $6 / 10$ fibroadenomas and $4 / 10$ phyllodes tumors. This finding was not statistically significant compared with the type 2 and type 3 signal intensity/time curves $(\mathrm{p}=0.371)$. Details of the MRI findings are summarized in table 3.

Of 72 fibroadenomas, 49 (68\%) were diagnosed as BI-RADS 3, $22(30 \%)$ as BI-RADS 4, and $1(1 \%)$ as BI-RADS 5. Among 70 phyllodes tumors, 12 (17\%) were classified as BI-RADS 3 and 58 (83\%) as BI-RADS 4. Fibroadenomas were more frequently classified as BI-RADS 3 (68.1\%) and phyllodes tumors as BI-RADS 4 (82.9\%), and these results were statistically significant $(\mathrm{p}<0.001)$.

\section{Discussion}

In the present study, mammographic, sonographic, and MRI features used to differentiate between fibroadenomas and phyllodes tumors were examined. In accordance with previous studies, phyllodes tumors were frequently larger than fibroadenomas [12, 13]. Our findings also suggested that tumor shape may be helpful for differentiating between fibroadenomas and phyllodes tumors. 


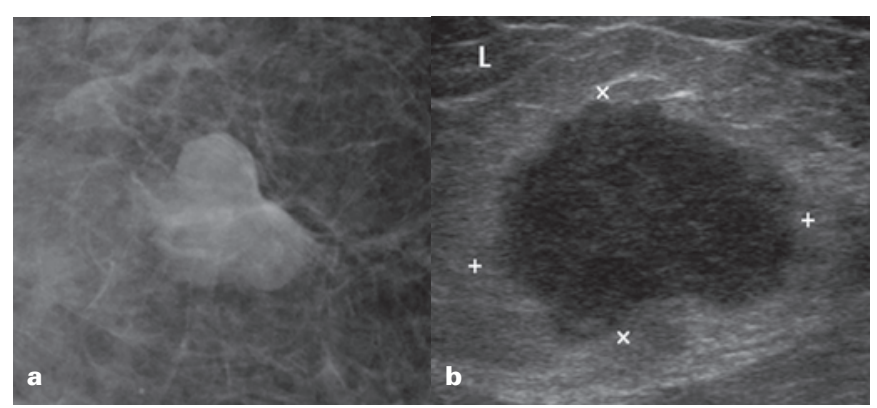

Fig. 1. a Mammogram of a 49-year-old woman indicating an irregular mass with partially indistinct margins. b Sonogram showed an oval-shaped hypoechoic mass with microlobulated margins and heterogeneous internal echogenicity. Histopathology indicated a benign phyllodes tumor.

Some groups reported that phyllodes tumors are frequently lobulated in shape $[14,15]$ while others found no significant difference in shape between fibroadenomas and phyllodes tumors. Both tumors tend to be oval or lobulated in shape $[6,8,9,12]$. However, in the present study, the lesion shape was classified according to the ACR BI-RADS Atlas, 5th edition, and thus the term 'irregular' corresponds to a lobulated shape. Consequently, fibroadenomas were frequently oval while phyllodes tumors were irregular on mammograms and sonograms (fig. 1a). Furthermore, $90 \%$ of phyllodes tumors were irregular while $60 \%$ of fibroadenomas were oval on MRI, although the results were not significant due to the small sample size.

Buchberger et al. [14] and Blanco et al. [15] reviewed the sonographic features of phyllodes tumors. In accordance with most findings in the literature, they reported that phyllodes tumors had circumscribed margins. However, in the present study, circumscribed margins were significantly more common in fibroadenomas than in phyllodes tumors which had microlobulated borders (fig. 1b). Chao et al. [16] reported that color Doppler could not distinguish between malignant, borderline, and benign phyllodes tumors. Our findings suggested that hypervascularity might be a significant feature of phyllodes tumors while fibroadenomas are more frequently hypovascular (supplemental fig. 1a, www.karger.com/? DOI=444377).

High density was reported to be a useful mammographic feature suggestive of phyllodes tumors due to the larger lesion size $[5,9$, 13], although this was not a significant finding in the present study. Previous studies yielded contradictory results regarding the presence or absence of intratumoral calcifications. Some studies indicated that fibroadenomas, especially long-standing lesions, more frequently contained calcifications [16] while others indicated no difference in frequency, as in the present study [5, 9].

Distortion, edema, or ductal ectasia of the breast parenchyma surrounding the mass are known characteristics suggestive of malignancy. In the present study, only a small number of cases (14\%) showed these characteristics, and therefore the results were not significant, although $86 \%$ were phyllodes tumors (fig. 2). On the other hand, 1 fibroadenoma was incorrectly classified as a BI-RADS 5 lesion because of distortion and edema of the surrounding paren-
Fig. 2. Mediolateral oblique view mammogram of a 44-year-old woman indicating a lobulated hyperdense mass with microlobulated margins. Distortion of the surrounding parenchyma and skin edema were also shown. Histopathology indicated a malignant phyllodes tumor.

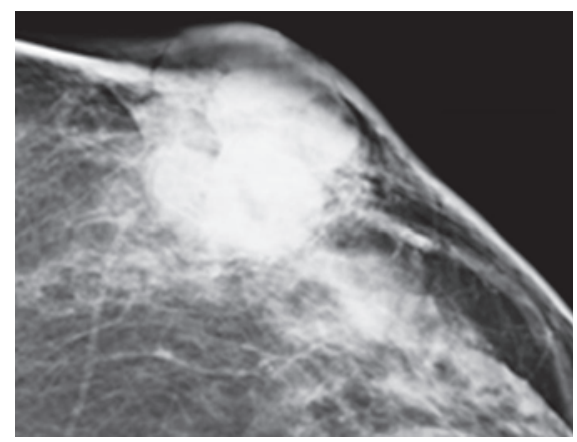

chyma in addition to indistinct margins. In this case, accompanying inflammatory changes due to mastitis, which disappeared on follow-up, led to misdiagnosis.

In the study by Wiratkapun et al. [5], most phyllodes tumors (85\%) were sonographically heterogeneous, as reported in other studies [5, 12, 13, 16-18]. Our study also showed that fibroadenomas were homogenously hypoechoic while phyllodes tumors showed complex/heterogeneous echo patterns, and this difference was significant. The posterior acoustic enhancement phenomenon is a sonographic feature that has been observed in $50-77 \%$ of phyllodes tumors in different studies $[9,14]$. This is explained by the presence of intramural cysts representing areas of degeneration and focal necrosis $[15,19]$. In accordance with the literature, posterior acoustic enhancement was more commonly detected in phyllodes tumors than in fibroadenomas in the present study (supplemental fig. 1a, www.karger.com/?DOI=444377). This was also supported by the MRI findings of the present study (supplemental fig. 1b, www.karger.com/?DOI=444377). The presence of internal cystic areas was significantly different between fibroadenomas and phyllodes tumors. Fibroadenomas were more frequently (50\%) associated with hypointense internal septations than with internal cystic areas on MRI (supplemental fig. 2, www.karger.com/? $D O I=444377)$. Internal septations were a typical MRI finding in fibroadenomas, with a frequency of $40 \%$ in 1 previous study [20]; yet, in some studies, septations were also seen in phyllodes tumors $[21,22]$. However, none of the 10 phyllodes tumors had any septations in the present study.

Previous studies described slowly enhancing (type 1) and suspiciously enhancing (types 2 and 3 ) phyllodes tumors at rates of up to 9 and $18 \%$, respectively [23,24]. Wurdinger et al. [25] reported that one-third of phyllodes tumors showed a typical malignant enhancement pattern. In the present study, signal intensity/time curve assessment was not significantly capable of differentiating between phyllodes tumors and fibroadenomas. However, the enhancement pattern seemed to be descriptive although not significant (supplemental fig. 2, www.karger.com/?DOI=444377). Homogeneous enhancement was observed in 8 of 10 fibroadenomas and in 7 of 10 phyllodes tumors.

There are several limitations to our study. First, its retrospective nature limited our ability to determine the Doppler sonographic features. The masses could not be evaluated for the resistive index value which has not been reported previously. It was not possible 
to determine whether the vascular distribution was central or peripheral. The small number of pathologically proven phyllodes tumors over the 13-year study period and the small number of masses evaluated by MRI were other limitations of our study preventing statistically significant results. In addition, demographic findings of the cases were not analyzed, as this study was based only on imaging findings. Fourth, histopathological types of phyllodes tumors were not considered, since previous studies failed to establish radiological characteristics that predict benign, borderline, or malignant cytology $[14,15]$.

\section{Conclusion}

The present study emphasized that tumor size $<3 \mathrm{~cm}$, ovoid shape, circumscribed margins, hypoechoic homogenous internal echo pattern, hypovascularity, and hypointense internal septations are more frequent in fibroadenoma. On the other hand, a tumor size $\geq 3 \mathrm{~cm}$, irregular shape, microlobulated borders, complex internal echo pattern, hypervascularity, and internal cystic areas on MRI were suggestive of phyllodes tumors. These findings could help radiologists to ascertain imaging-histological concordance and guide clinicians in their decision making regarding adequate follow-up or whether a biopsy is necessary.

\section{Online Supplemental Material}

Supplemental Fig. 1. Doppler sonogram of a 41 -year-old woman a indicating an oval, microlobulated, hypervascular mass with a complex internal echo pattern and hypoechoic internal cysts; b T2-weighted turbo spin echo sequence with fat suppression showed hyperintense cystic areas. Histopathology indicated a borderline phyllodes tumor.

Supplemental Fig. 2. Postcontrast dynamic magnetic resonance image of a 19-year-old woman indicating an oval-shaped mass with circumscribed margin, homogenous enhancement, and unenhanced hypointense internal septations. A benign type signal intensity/time curve was detected. Histopathology indicated a juvenile fibroadenoma.

To access the online supplemental material, please refer to www.karger. com/?DOI=444377.

\section{Disclosure Statement}

The authors report no conflict of interest.

\section{References}

1 Anderson BO, Lawton TJ, Lehman CD, Moe RE: Phyllodes tumors; in Harris JR, Lippman ME, Morrow M, Osborne CK (eds.): Diseases of the Breast, 3rd ed. Philadelphia, PA, Lippincott Williams \& Wilkins, 2004, pp. 991-1006.

2 Gatta G, Iaselli F, Parlato V, Di Grezia G, Grassi R, Rotondo A: Differential diagnosis between fibroadenoma, giant fibroadenoma and phyllodes tumour: sonographic features and core needle biopsy. Radiol Med 2011;116:905-918.

3 Abe M, Miyata S, Nishimura S, Iijima K, Makita M, Akiyama $\mathrm{F}$, Iwase $\mathrm{T}$ : Malignant transformation of breast fibroadenoma to malignant phyllodes tumor: long-term outcome of 36 malignant phyllodes tumors. Breast Cancer 2011;18:268-272.

4 Reinfuss M, Mitus J, Duda K, Stelmach A, Rys J, Smolak K: The treatment and prognosis of patients with phyllodes tumor of the breast: an analysis of 170 cases. Cancer 1996;77:910-916.

5 Wiratkapun C, Piyapan P, Lertsithichai P, Larbcharoensub N: Fibroadenoma versus phyllodes tumor: distinguishing factors in patients diagnosed with fibroepithelial lesions after a core needle biopsy. Diagn Interv Radiol 2014;20:27-33.

6 Jacklin RK, Ridgway PF, Ziprin P, Healy V, Hadjiminas D, Darzi A: Optimising preoperative diagnosis in phyllodes tumour of the breast. J Clin Pathol 2006;59: 454-459.

7 Dillon MF, Quinn CM, McDermott EW, O’Doherty A, O'Higgins N, Hill AD: Needle core biopsy in the diagnosis of phyllodes neoplasm. Surgery 2006; 140:779784.
Lee AH, Hodi Z, Ellis IO, Elston CW: Histological features useful in the distinction of phyllodes tumour and fibroadenoma on needle core biopsy of the breast. Histopathology 2007;51:336-344.

9 Yllmaz E, Sal S, Lebe B: Differentiation of phyllodes tumors versus fibroadenomas. Mammographic and sonographic features. Acta Radiol 2002;43:34-39.

10 Feder JM, de Paredes ES, Hogge JP, Wilken JJ: Unusual breast lesions: radiologic-pathologic correlation. Radiographics 1999;19:11-26.

11 Yabuchi H, Soeda H, Matsuo Y, Okafuji T, Eguchi T, Sakai S, Kuroki S, Tokunaga E, Ohno S, Nishiyama K, Hatakenaka M, Honda H: Phyllodes tumor of the breast: correlation between MR findings and histologic grade. Radiology 2006;241:702-709.

12 Bode MK, Rissanen T, Apaja-Sarkkinen M: Ultrasonography and core needle biopsy in the differential diagnosis of fibroadenoma and tumor phyllodes. Acta Radiol 2007;48:708-713.

13 Foxcroft LM, Evans EB, Porter AJ: Difficulties in the preoperative diagnosis of phyllodes tumours of the breast: a study of 84 cases. Breast 2007;16:27-37.

14 Buchberger W, Strasser K, Heim K, Müller E, Schröcksnadel $\mathrm{H}$ : Phyllodes tumor: findings on mammography, sonography and aspiration cytology in 10 cases. AJR Am J Roentgenol 1991;157:715-719.

15 Jorge Blanco A, Vargas Serrano B, Rodríguez Romero R, Martínez Cendejas E: Phyllodes tumors of the breast. Eur Radiol 1999;9:356-360.

16 Chao TC, Lo YF, Chen SC, Chen MF: Sonographic features of phyllodes tumors of the breast. Ultrasound Obstet Gynecol 2002;20:64-71.
17 Stavros AT: Atypical, high-risk, premalignant, and locally aggressive lesions; in Stavros AT (ed.): Breast Ultrasound, 1st ed. Philadelphia, PA, Lippincott Williams \& Wilkins, 2004, pp. 689-711.

18 Chao TC, Lo YF, Chen SC, Chen MF: Phyllodes tumors of the breast. Eur Radiol 2003;13:88-93.

19 Harper AP, Kelly-Fry E, Noe JS, Bies JR, Jackson VP Ultrasound in the evaluation of solid breast masses. Radiology 1983;146:731-736.

20 Hochmann MG, Orel SG, Powell CM, Schnall MD, Reynolds CA, White LN: Fibroadenoma: MR imaging appearances with radiologic-histopathologic correlation. Radiology 1997;204:123-129.

21 Ogawa Y, Nishioka A, Tsuboi N, Yoshida D, Inomata T, Yoshida S, Moriki T, Toki T: Dynamic MR appearance of benign phyllodes tumor of the breast in a 20-year-old woman. Radiat Med 1997;15:247-250

22 Kinoshita T, Fukutomi T, Kubochi K: Magnetic resonance imaging of benign phyllodes tumors of the breast. Breast J 2004;10:232-236.

23 Kuhl CK, Mielcareck P, Klaschik S, et al.: Dynamic breast MR imaging: are signal intensity time course data useful for differential diagnosis of enhancing lesion? Radiology 1999;211:101-110.

24 Boetes C, Strijk SP, Holland R, Barentsz JO, Van der Sluis RF, Ruijs JHJ: False-negative MR imaging of malignant breast tumors. Eur Radiol 1997;7:1231-1234.

25 Wurdinger S, Herzog AB, Fischer DR, Marx C, Raabe G, Schneider A, Kaiser WA: Differentiation of phyllodes breast tumors from fibroadenomas on MRI. AJR Am J Roentgenol 2005;185:1317-1321. 